\title{
Del fútbol en Ecuador: Un análisis sociopolítico del "Jugador número 12" aplicado a la capital
}

\author{
Of soccer in Ecuador: A sociopolitical analysis of the \\ "Player number 12 " applied to the capital
}

\author{
Santiago Sebastián Salazar López \\ Máster en Relaciones Internacionales, Escuela Europea de Dirección y Empresa- EUDE Bussines school, Estudiante de \\ Maestría de Investigación en Sociología Política de la FLACSO- Ecuador \\ Email: santiagosalazar9512@gmail.com
}

Doi: https://doi.org/10.22267/rceilat.214849.96

\section{Resumen}

Sociología y Deporte siempre fueron una combinación compleja desde las ramas de estudio de las Ciencias Sociales, en la actual amalgama de estudios infinitos dentro de múltiples campos, las prácticas deportivas y sus derivaciones (entendidas como efectos) han dado un salto a otro tipo de complejidades que van más allá de las lógicas corporales y de competencia que se nos habían enseñado dentro del rol del juego. Existe un riquísimo potencial que responde a través del deporte a diversos fenómenos porque refleja otros comportamientos sociales y culturales que no se tuvieron en consideración en tiempos pasados.

Desde hace décadas, varios y varias estudiosas sobre deporte y la sociedad, empezaron a indagar por estas temáticas, e incurrieron también en el oficio de la investigación referente a la historia, pero también en la violencia en el fútbol para conectarlas desde las ramas sociales. En ese sentido, este análisis pretende desde el ámbito sociopolítico comprender tanto el contexto como las dimensiones de ese 'Jugador Número 12' (hinchas/barras) en la ciudad de Quito, al igual que, expresar otras pautas para comprender las dimensiones de la violencia desde la óptica de las Ciencias Sociales. Esta investigación corresponde a un proceso que data del 2002 hasta el 2020, y combina metodológicamente componentes cualitativos, al igual que el trabajo con involucrados de los hinchas de Liga, Nacional, Aucas y también analiza documentos fuente-secundarios, y la prensa de la ciudad. La conclusión principal radica en que: los fenómenos relacionados con violencia y fútbol, no son un producto siempre ligado a las barras o hinchadas, sino que responden también a otro tipo de sentidos y lógicas muchas veces ignoradas o difundidas con explosividad. Hoy asistimos a ejercicios de resignificación que deberían plantearse en consideración y ganarse un espacio académico tal como veremos a continuación.

Palabras Clave: Barras; Hinchas; Fútbol; Violencias; Sociología del deporte; Estudios sociales y culturales sobre deporte. 


\begin{abstract}
Sociology and Sports have always been a complex combination from the study branches of Social Sciences, in the current amalgam of infinite studies within multiple fields, sports practices and their derivations (understood as effects) have taken a leap to other types of complexities that go beyond the body and competition logics that we had been taught within the role of the game. There is a very rich potential that responds through sport to various phenomena because it reflects other social and cultural behaviors that were not considered in the past.

For decades, several and various scholars on sport and society, began to investigate these issues, and also incurred in the office of research related to history, but also in violence in soccer to connect them from the social branches. In this sense, this analysis aims from the socio-political sphere to understand both the context and the dimensions of that 'Player Number 12' (fans / bars) in the city of Quito, as well as expressing other guidelines to understand the dimensions of violence from the perspective of Social Sciences. This research corresponds to a process dating from 2002 to 2020, and methodologically combines qualitative components, as well as the work with stakeholders of the fans of Liga, Nacional, Aucas and also analyzes source-secondary documents, and the press of the city. The main conclusion is that: the phenomena related to violence and football are not a product always linked to the bars or inflated, but also respond to other types of senses and logics that are often ignored or disseminated with explosiveness. Today we attend resignification exercises that should be considered and earn an academic space as we will see below.
\end{abstract}

Keywords: Soccer bars; Fans; Violence; Sociology of sport; Social and cultural studies on sport.

\section{Introducción: De hooligans y barras bravas}

De la osada travesía de Victoriano Agustín Caffarena, deriva el denominativo de "jugador número 12". La historia relata que siguió en barco por mitad del mundo al Boca Juniors que, por 1925 bajo las directrices de la Asociación Argentina de Fútbol, se comprometió a enviar a Europa a un equipo representante del país para disputar compromisos intercontinentales; Victoriano, aportó económicamente para que la mayoría de la plantilla viajase en barco alrededor de 22 días, además del pago de su pasaje y el desempeño de roles que a lo mejor no le eran competentes, pero que resulta- ron determinantes para el equipo: era el masajista, utilero, técnico, delegado, aguatero e inclusive, consiguió un carnet del diario El Telégrafo que le acreditaba como periodista del equipo. Antonio Cerroti, el delantero de Boca de la época y perteneciente a la delegación, lo llamó "jugador número 12 ”, pues argumentaba que, sin su apoyo, la grandiosa gira de 1925 (de la cual ganaron 15 de 19 encuentros) hubiere sido imposible. Caffarena volvió para convertirse en socio vitalicio del club, y en 1955 Boca Juniors de Argentina le entregó una placa, reconociéndolo como el "Jugador Número 12” (Lisotto, 2018)

Más allá de un ejercicio físico- tác- 
tico sobre el planteamiento de estrategias dentro del terreno de juego, es el espectador quien dota de sentido a la práctica, pues sin los simpatizantes, el fútbol no tuviese la popularidad e importancia de la que hoy goza. Esta condición cobra sentido por una suerte de cambios producidos en el desarrollo progresivo del fútbol como una actividad que encaja tanto en el ocio y espectáculo, producidos dentro del marco del proceso civilizatorio (Elias \& Dunning, 1992). Lo masivo del suceso, también comprende las formas de catarsis en las que, los obreros en sus tiempos libres después del trabajo en las fábricas, disfrutaban del juego a la manera de jugadores y espectadores, además de marcar los inicios de un fútbol vinculado con un carácter popular y reconocido.

Estos comienzos de forma amateur y citadina, contaron con la rápida proliferación de equipos y aficionados a nivel mundial, no obstante, trajeron consigo (a la manera de efectos secundarios) tipos de violencias. La mayoría escogieron el casco urbano de la ciudad como foco central de sus manifestaciones. Estas son una serie de contingencias y contenciones que poco a poco se (mal) normalizaron en el espectáculo y que se trasladaron a múltiples tópicos de distinta procedencia: agresiones de corte físico, simbólico, verbal y de género. Los orígenes se remontan a la Inglaterra de la década de los 60 y 70, atribuidos a quienes denominaron como Hooligans, y, a la Argentina de los $50 \mathrm{y}$ fuertes picos de retorno en los 80 con los Barras bravas. Conforme a la explicación de
Dunning, Murphy \& Williams (1992), se partirá de una premisa clásica que manifiesta que, entre mientras más crecían los clubes, más crecían las aficiones y "el deseo de vengarse por la derrota en la lucha durante un partido anterior, o el de un grupo de aficionados por derribar a otro del pedestal en el que los medios de comunicación lo han colocado" (Dunning, Murphy, \& Williams, 1992, p. 328). El término hooligan es polémico en tanto a sus orígenes, pero fue Inglaterra quien lo asoció a la delincuencia y marginalidad social. Arthur Conan Doyle utiliza al 'hooliganismo' para referirse a actos vandálicos y violentos en su relato corto: The adventure of the six Napoleons en 1904" (Redondo 2016) Omar Eidelstein (2016) comprende que una versión aceptada recae sobre la figura de un ciudadano irlandés:

Edward Hooligan, que algunos lo dan viviendo en lo peor del East London y otros en lo todavía más recalcitrante de la zona norte, refugio por aquella época de todo tipo de malvivientes. [...] Se le había hecho costumbre no trabajar bajo ningún punto de vista, emborracharse todo lo más que pudiera y no encontrar nada más entretenido que aprovechar las grandes aglomeraciones del fútbol, los sábados a la tarde, para agarrarse a golpes con quien fuera y sin importarle cuántos eran ni a qué hospital podía ir a parar. [...] Su fama salió de los alrededores de aquellas viejas canchas y el lenguaje popular comenzó a motejar de hooligan a cuanto haragán, borrachín o pendenciero, por separado y ni qué decir las tres cosas juntas, apareciera por cualquier 
barriada londinense. (Eidelstein, 2016, p. 11)

Esta figura vandálica y antagónica, marcó la producción del miedo dentro y fuera de la Inglaterra de 1960 y 1970 (Hobbs \& Robins, 1991, págs. 53-85) para que, rápidamente desembocase en el epicentro del canal de Manchester, que geográficamente se conecta de forma fluvial y terrestre con el sector de Liverpool, sitios originarios tanto de disputas como de conformaciones de hooligans, siendo precursores. (pero estas disputas de corte histórico competen a otras líneas que también se trabajan desde la sociología del deporte)

Del otro lado del globo, años más tarde, un proceso similar se gestionaba en el cono sur latinoamericano, pero veamos primero sus denominativos. El término barra, puede traducirse en el sentido de algo duro, infranqueable, rudo y fuerte; el apelativo de brava, ya es producto de otras situaciones en particular que derivan de Argentina. Uno de los primeros hechos data de 1958, que aún remembra la historia del joven Linker, un hincha de Boca a quien "se vio tirado en el suelo, víctima del impacto de una bomba de gases en su cabeza [...] Murió unas horas después en el hospital Salaberry, de Buenos Aires" (Szlifman 2020). El autor señala que, los diarios calificaron el hecho como bochornoso y atribuido a un pequeño grupo de exaltados que, denominarían como "barras fuertes", públicas y conocidas, se modifican de forma drástica las presentaciones y percepciones que tenía la prensa sobre los sucesos y los aficionados. Casi una década después, el calificativo de barras fuertes cambia por el de barras bravas: "el apelativo de barras bravas surgió a partir de un hecho trágico [...] El 9 de abril de 1967 fue asesinado a golpes Héctor Souto de 15 años de edad, seguidor de Racing Club, por uno de los líderes de la barra de Huracán" (Castro 2013, p.168). El ingreso de Souto según se relata, fue por equivocación a la tribuna de Huracán, generando el infortunio de su muerte en breves instantes.

El barrismo en Quito comienza en los años 90 con Armagedón (Aucas), Muerte Blanca (Liga), Marea Roja (Nacional) y Mafia Azul Grana (Deportivo Quito), como una suerte del efecto que Ramírez (2017) ha denominado como "culturas viajeras", expresiones futboleras y barristas que subieron desde el cono sur argentino/chileno, para adentrarse en los países de la región. No obstante, la primera barra en Ecuador, llega a Guayaquil, siendo pionera la Boca del Pozo (Emelec) en 1980 con la influencia de los viajes de Giussepe Cavanna el líder de la barra de la época. Como veremos al final de las reflexiones, el efecto barrista hoy comprende otras formas de asociatividad dentro del contexto público.

Como se ha visto, es imposible negar la presencia de alguna forma de violencia en las hinchadas, que han sido categorizadas (al menos en la región) como 'barras bravas'. Desde la socioantropología del deporte, se han dado algunas explicaciones a este comportamiento. Para Dunning (1992) uno de los factores explicativos de la conducta violenta de los hinchas de fútbol está relacionada de una manera central con normas de masculinidad. Otros autores han planteado que la violencia en los graderíos puede ser entendida como una "agresión ritualizada" en la medida que los actos violentos señalan una disputa por una 
identidad, un imaginario, un territorio simbólico y a veces real (Alabarces, 2000); una representación de los jóvenes de una agresividad masculina en un contexto de exclusión económica resultante del modelo neoliberal (Magazine, 2008); un espacio de producción y representación de una 'lógica simbólica de masculinidad violenta' (Ramírez, 2010) o producto de la pasión colectiva que se vive en los graderíos dado que el fútbol parece estar diseñado para expresar sentimientos extremos y emociones 'ilógicas' como la pasión (Bromberger, 1994).

Algunas miradas hablan incluso de un proceso de neotribalización o "tribus urbanas", las mismas que "se rigen por la afectividad entre los pares, se ligan a un tótem común, que en el caso de los hinchas organizados son sus tiempos y sus propias barras vistas como entidades autónomas (Santos, 2003).

Analizaré el caso ecuatoriano, en torno a los primeros sucesos publicados desde prensa con dos de los diarios más importantes, El Comercio (Quito) y El Universo (Guayaquil), cuyos registros aparecieron ya en los primeros años del cambio de siglo, siendo el 2002 uno de los hitos fundacionales de la violencia ligada al fútbol, cuyo epicentro radica en la ciudad de Guayaquil. Con el trabajo de artesanía intelectual, se construyó una metodología que permitió armar un rompecabezas para darle una lectura parcial al fenómeno.

\section{Método}

En este estudio predominó el uso de un enfoque de corte cualitativo, entendido como "una perspectiva interpretativa centrada en el entendimiento del significado de las acciones de seres vivos, sobre todo de los humanos y sus instituciones (busca interpretar lo que va captando activamente)" (Sampieri, Fernández, \& Baptista, 2014, pág. 9). Se emplearon entonces, técnicas de recolección de información como el análisis documental y acercamientos directos con entrevistas a hinchas y barristas de la ciudad de Quito. La primera técnica, permite la construcción abstracta de la realidad para explicar los fenómenos que se encuentran dentro de la misma a una escala social, es esencial para revelar cómo se configuran en la norma y el papel, ciertas percepciones que de la institucionalidad emanan, además de proveer el rastreo de fuentes secundarias como: producción de artículos, producción académica, archivo histórico en prensa, fotos, notas, relatos, documentos públicos entre otros.

De la segunda, se permitieron comprender y aproximarse a una descripción del conocimiento referente a ciertas historias y experiencias de vida. Si bien en su mayoría traslapan un carácter anecdotario de gente identificada con equipos como Liga de Quito, Aucas y El Nacional, fueron proveedores de información (fuente) de primer nivel que comprenden la configuración (parcial) de los componentes de las violencias y las riva- 
lidades y cuál ha sido la articulación desde el espectro político. Esta lógica, también permitió una inmersión de contacto directo en la mayoría de los casos para esclarecer mejor las figuraciones y asociatividades dentro y fuera de las canchas.

Este trabajo fue una apuesta arriesgada, pues, no fue sino hasta hace muy poco tiempo que, el estudio de los deportes (o al menos en el contexto ecuatoriano) comenzó a tener cabida en los centros académicos y a considerarse como una actividad de investigación rigurosa. Estas páginas intentarán desde diversos puntos, ampliar los horizontes y líneas de trabajo que hoy consideramos también urgentes y que son propicias para la comprensión de ciertos fenómenos que no sólo calan en el ámbito táctico- fisiológicodeportivo, sino que contemplan otro tipo de apreciaciones desde el aspecto exógeno o ignorado.

\section{Resultados}

\section{Punto de partida: La sociología del deporte y los estudios sociales y cul- turales sobre deporte}

Me parece prioritario aclarar que, sin el aporte de la sociología fundamental de Norbert Elias, la sociología del deporte difícilmente podría ser posible. En el epicentro europeo, Elias (2008) parte de la explicación de postulados que encajan como las piezas en su rompecabezas para hacer más que válida la teoría, señalando que, la sociología implica una tarea de ocupación de los problemas de la socie- dad que recae sobre quien la reflexiona y la estudia, estimando el supuesto de que las personas que forman parte de un medio (que muchas veces no es percibido por el ego) conviven en construcción heterogénea con otras personas: "la sociedad que con tanta frecuencia se opone mentalmente al individuo, está integrada totalmente por individuos, uno de esos, es uno mismo" (Elías, 2008, p. 14): Somos parte de una mezcolanza, no definida, no delimitada, que permanece en flujo constante y que se compone de individuos que están en constante interacción.

El enfoque de Elias propone, la reflexión sobre aquello que conocemos como sociedad desde una mirada egocéntrica, situando al individuo en tanto a productor y receptor de "interdependencias a las que denomina «figuraciones», con lo que pretende superar la arbitrariedad de considerar la diferencia entre individuo y sociedad" (García, Legardera, \& Puig, 2017, p.29). Por fuera de la perspectiva tradicional, para el autor, el individuo no pertenece a una concepción holística de la sociedad, por el contrario, tiene capacidad para pensar a la misma y a las realidades mediante acciones y configuraciones humanas que le permiten acercarse en diferentes direcciones. Quiebra entonces con el enfoque sociológico funcionalista, para pasar a un trabajo relacional:

Muchas personas individuales que, por su alineamiento elemental, sus vinculaciones y su dependencia recíproca están ligadas unas a otras de modo más diverso y, en consecuen- 
cia, constituyen entre sí entramados de interdependencia o figuraciones con equilibrios de poder más o menos inestables de tipo más variado como, por ejemplo, familias, escuelas, ciudades, capas sociales o estado. Cada uno de estos individuos es, como se expresa en términos objetivadores, un «ego» o un «yo». Uno mismo se cuenta entre estos individuos. (Elías, 2008, p. 16)

En el epicentro sudamericano, una suerte similar tuvieron los "estudios sociales y culturales sobre deporte", que tienen cierta parsimonia con la sociología del deporte europea, pero poseen otras explicaciones que dibujan otro tipo de horizontes y se aterrizan más en el contexto de la región. Cuando el académico argentino Pablo Alabarces realizó sus estudios sobre la cultura popular en Inglaterra, aprovechó la oportunidad para empaparse también sobre las líneas que ya los ingleses habían escrito sobre deporte. El maestro Alabarces, respondía en su momento a una etapa de aproximaciones temáticas sobre la interpretación y particularización de algunos fenómenos deportivos relacionados con las cuestiones de la identidad nacional vinculada con el fútbol argentino, "esta fue una palabra clave que organizó 10, 15 años de trabajo latinoamericano sobre cómo los deportes habían contribuido en mayor, menor medida, más sólido, más precariamente a lo que podemos llamar: narrativas de identidad, nacionales, locales, regionales y también étnicas" (Alabarces, Clase con Pablo Alabarces, 2020)
Desde la década de los ochenta, aparecieron los primeros documentos que sirvieron de base para darle sentido a la cuestión. En 1982 el grupo de antropólogos de Roberto DaMatta escribió en colectivo "O universo do futebol", referente a fútbol y cultura brasileña, los primeros artículos (tan claves) de Eduardo Archetti de 1984 sobre la cultura del aguante, y de colegas que complementarían la cuestión con preceptos antropológicos como Verónica Moreira y José Garriga Zucal. El maestro Alabarces (2014) señaló:

Lo cierto es que a mediados de los noventa estudié sociología de la cultura, a finales de 1998 estaba haciendo un doctorado en Inglaterra, en la bella ciudad de Bringhton. Así me hice sociólogo de alguna manera. $\mathrm{O}$ me hicieron sociólogo los temas y los enfoques. Como nada se había inventado sobre fútbol, había que hacerlo todo: entonces, en esa década inventamos la sociología y los estudios sociales y culturales sobre deporte, casi en toda América Latina. (Alabarces, 2014, págs. 22-23)

Sólo apenas 20 o 25 años después se logró posicionar una agenda que hoy está mejor consolidada, “en 1995, 96, cuando escribí las primeras cosas, la cantidad de relatos ficcionales dedicados al fútbol y de literatura argentina y uruguaya, se podía contar con los dedos de no digo una mano, sino de dos manos. Estaba absolutamente reducido en términos ficcionales, eran muy pocos relatos" (Alabarces, 2020). No obstante, hoy, los estudios sociales y culturales sobre deporte, permiten:

La comprensión de los aspectos cul- 
turales, históricos, sociales, educacionales y filosóficos del fenómeno deportivo. [...] busca abordar estos aspectos a partir de la lectura y discusión de obras clásicas y de autores que, desde los aportes de distintas áreas de las Ciencias Sociales y Humanas, buscan analizar cómo los distintos hechos culturales y sociales permean las distintas manifestaciones deportivas. Entre los temas abordados se pueden mencionar las relaciones que se establecen entre deporte y trabajo, la transformación del deporte en una forma de espectáculo, y las reflexiones sobre la relación entre deporte y estética. También se proponen espacios de cine - debate texto, donde a partir de una película o documental se seleccionará un texto temático para analizarla. (Seminario de estudios sociales y culturales sobre deporte, 2020)

\section{Del fútbol ecuatoriano: Inicios}

Como lo explican las crónicas históricas y parte de la comunidad académica que ha indagado por la cuestión en el caso de Ecuador, el fútbol llegó al país por el Puerto de Guayaquil en la última década del siglo XIX ${ }^{1}$, este escenario fue el foco propicio de intercambios comerciales, rutas de transporte y efectos migratorios por diferentes situaciones. Los hermanos Alfredo y Roberto Wright fueron precursores de estos intentos "importan los primeros balones en 1899 [...] se establecen en Guayaquil e intentan organizar partidos y equipos locales." (Bustamante 2006, 38). El contexto de la época entraba en una etapa de "mo-

1 Véase Carrión (2006) dernidad" proveniente de criterios europeos y norteamericanos, el ensanchado progreso de la perspectiva "cosmopolita" del mundo, coincidía con la tendencia Cobdenista ${ }^{2}$ del siglo XIX en tanto profesaba la defensa del librecambio, y el uso del comercio como conductor para la paz universal:

La conciencia social y la cultura económico-política de las clases educadas y de la sociedad "culta" de la época se halla todavía plenamente marcada por la admiración sin límites del Cobdenismo". La Revolución Liberal, había terminado de abrir las puertas a la irrestricta aceptación pública del laicismo y de la consiguiente admiración acrítica frente a todo lo que venía del "mundo cosmopolita del progreso", del cual, por cierto, Inglaterra y los Estados Unidos aparecían como portadoras preeminentes. En cierto sentido, puede especularse que la entrada del fútbol coincide con una época en donde ser "moderno", liberal y contemporáneo, era "estar a tono" con las novedades del mundo del progreso, el cual, en dicha época era lo que desembarcaba en los muelles. (Bustamante 2006, 39-40)
2 Tendencia que toma el nombre de Richard Cobden, un autor y político británico del Siglo XIX que se convirtió en el más apasionado y epónimo defensor del librecambismo a ultranza y de la teoría ricardiana de las ventajas comparativas. Cobden pensaba que la libertad de comercio traería e! progreso acelerado de toda la humanidad y abriría las puertas de la paz universal. (Bustamante 2006, 40) 
Uno de los registros de los primeros clubes ${ }^{3}$ data de 1902 "la fundación del Club Sport Ecuador, el día 22 de julio de $1902[\ldots]$ tuvo una existencia breve y desapareció al calor de diferencias políticas entre sus integrantes" (Velásquez 2006, 108).

En paralelo, en la ciudad de Quito también de a pocos el fútbol ganaba popularidad. La tesis de José Perugachi (2018) también sostiene que el fútbol llegó al país de la mano de inversiones extranjeras, el fútbol al interior ecuatoriano en el caso de la sierra, tuvo como un fuerte conducto regular la influencia de construcciones como la red ferroviaria. El inicio de las obras bajo la dirección de profesionales ingleses, mantuvo una estrecha relación entre el imaginario del fútbol y la modernidad (en concordancia con Bustamante y Carrión) cuyas actividades de ocio (en torno a las novedades del mundo) se asociaban al gusto de las modas, hábitos, música o lecturas de corte inglés o norteamericano, además de pasatiempos entre los cuales se encontraba el fútbol amateur como una forma de esparcimiento en el

3 Véase la tesis de Arévalo y Adalí (2019) para mayor profundidad: " 23 de abril de ese mismo año cuando se funda el Guayaquil Sport Club, dando lugar a la práctica de fútbol en Ecuador, posteriormente se crea el Club Sport Ecuador y el Club de la Asociación de Empleados, mientras que un año más tarde tendrían lugar los primeros encuentros entre estos equipos de manera oficial que darían paso a que durante la primera década del siglo XX se consolidaran nuevos equipos entre los que destacan: la Asociación de Empleados de Guayaquil, Unión y Gimnástico, Libertador Bolívar, mientras que en Quito aparecen equipos como el Sport Club Quito y Gladiador (Arévalo y Adalí 2019, 56) tiempo libre de los obreros (Perugachi 2018, 39):

En el transporte (puertos y ferrocarril), minería (oro, petróleo y Aucas) y energía (electricidad, Emelec) [...] La revolución liberal, la construcción del ferrocarril, aportaron significativamente en lo político como en lo social [...] acercó a dos regiones antagónicas y rivales: La Sierra y la Costa (Perugachi 2018, 39)

Otro hito importante del fútbol en Quito, según Velásquez (2006) es lo acontecido con unos colegiales que habitaban en un barrio popular de la ciudad “"los guambras” se organizaron e iniciaron sus prácticas en el tradicional Barrio de San Marcos, pasando luego a establecerse en El Ejido" (Velásquez 2006, 108- 109). Algunos registros aducen a que les llamaban los ““ "chirioques" de San Marcos [...] un grupo de estudiantes del colegio Mejía, [...] estaba conformado por unos 40 muchachos." (Velásquez 2006, 109).

Los del Mejía fundaron uno de los primeros equipos de la ciudad el "Sport Club Quito" en 1908, después de que en 1907 tuvieren un primer acercamiento con el esférico, "Dicen los historiadores del balompié ecuatoriano que la primera bola de fútbol una "T" de fabricación inglesa llegó a la ciudad de la Plaza Grande en $1907^{4}$

4 La tesis de Randy Hill (2015) también señala que durante la época, en Quito el fútbol llegó en 1907 aproximadamente durante la administración constitucional de Eloy Alfaro, 44 años después de que llegase a Inglaterra o se tuviere un registro oficial: "Un comerciante francés de apellido Rangel 
por gestión de un vecino comerciante de apellido Rangel” (Velásquez 2006, 109). Poco tiempo después en el Mejía, importaron el primer reglamento del juego.

Versiones convergentes como la de Ribadeneira (2008) sostienen que el origen del fútbol quiteño se produjo en el barrio San Sebastián "con grupos enteros de guambras que llevaron de un lado a otro una especie de redonda un Ishpapuro" envuelto en trapos- en medio del gusto, y a veces la rabia, de los vecinos", comenzó el fútbol" (Ribadeneira 2008, 31)

Lo cierto es que los estudiantes del Mejía fueron los primeros cultores del fútbol, que no era conocido como fútbol, sino como "las "arriadas", porque los jugadores, divididos en dos bandos, debían arriar la pelota, con los pies, hacia la línea contraria. Ganaba el equipo que más veces llegaba a la línea (meta) contraria (Bustamente 2002, 28). Tal parece que las arriadas tenían lugar en dos de las avenidas (hoy) reconocidas de la ciudad, "Un bando cuidaba la línea sur, actualmente avenida Tarqui, mientras el otro bando cuidaba la línea norte, la actual avenida Patria. La cancha era de casi un kilómetro en el hoy parque

llegó a Quito con una pelota T inglesa, sin saber de su magna utilidad; la regaló a sus amigos, muchachos estudiantes del laico Colegio Mejía (fundado por Eloy Alfaro). Este deporte sacudió a la conventual ciudad, porque, para jugarlo, había que dejar al descubierto varias partes del cuerpo, una suerte de pecado mortal para las citadinas feligreses de esos días" (Hiil 2015, 23) de El Ejido” (Bustamente 2002, 28). De la experiencia de los estudiantes del Mejía y otros eventos como la presencia extranjera, la inversión de capitales y el reconocimiento del fútbol dentro de espacios también de esparcimiento libre de los obreros, podría lanzarse una hipótesis preliminar: el fútbol en Quito nace rápidamente con un proceso de difusión explosivo (al igual que su similar, en tanto a puntos concéntricos y estratégicos del país como Guayaquil) además de que permeó espacios asociativos que antes (quizás) no se habrían contemplado.

\section{Del fútbol en Ecuador: etapa de po- pularización}

El fuerte del contexto económico ecuatoriano siempre se ha permeado por las exportaciones de banano, petróleo y camarón, esto es importante porque explica también cómo los periodos de inflación durante los $70 \mathrm{y}$ 80, provocaron la inserción de las lógicas del modelo neoliberal que otorgarían al mercado un papel rimbombante, el fútbol no pasó exento de esta dinámica. La espectacularización del mercado, que también permearía los espacios del ocio y el espectáculo (en términos de Norbert Elias), le otorgó al fútbol una fuerte popularidad como una de las tantas cartas en la baraja de dispersión en el espacio y tiempo.

Daniel Pontón y Carlos Pontón (2006) entienden en lo progresivo de ese segmento el desarrollo de una etapa romántica que duraría hasta 1970. Tiene sentido en tanto los autores aducen a la existencia del legado de 
las construcciones del pasado, con un avance progresivo de la organización deportiva y social con un carácter más formal con los primeros intentos de profesionalización de fútbol y el surgimiento de las primeras federaciones deportivas de carácter provincial: La Federación Deportiva de Guayas (FDG) en 1950 y la Asociación de Fútbol no Amateur de Pichincha (AFNA) en 1954. Posteriormente, en 1957 se registra el primer campeonato nacional, oficial, regulado y de carácter no amateur disputado en el país (Pontón y Pontón, 2006):

Empieza con el aparecimiento del profesionalismo en el fútbol del Ecuador y sus primeros ídolos e idolatrías locales a principios de los años 50; se consolida con la presencia de los primeros campeonatos nacionales a finales de los años cincuenta y principio de los años 60 y culmina en los años 70 con la expansión de la popularidad de los equipos a nivel nacional [...] La historia del profesionalismo del fútbol en Ecuador comienza en el año 1950 en Guayaquil, con la creación de la Federación Deportiva del Guayas (FDG) y en 1954 en Pichincha con la fundación de la Asociación de Fútbol no Amateur de Pichincha (AFNA). Estas fechas si bien son un hito importante en nuestra historia futbolera, como una expresión de modernización del deporte en la sociedad ecuatoriana, el legado del amateurismo en cuanto a los orígenes de las hinchadas es importante. (Pontón y Pontón, 2006, págs. 79-81)

Para el caso quiteño, eran el Aucas y Deportivo Universitario (hoy Liga de Quito) quienes se disputaron los cam- peonatos, dejando con los títulos de 1945, 1946, 1947, 1948, 1949 y 1951 al primero, y al segundo los de1932, 1952 y 1953. Estos campeonatos los regulaban las federaciones deportivas regionales como tal, pero sólo hasta 1968 la Federación Nacional de Fútbol logró aglutinar un campeonato nacional sin las paralelas competencias de provincia, este es un punto crucial también en la conformación de las aficiones ecuatorianas (Ramírez, 2017, p. 159). La etapa futbolera como forma de ocio y espectáculo, permitió la conformación también de sentidos de identificación de los ecuatorianos con los equipos de fútbol de la época, surgieron entonces en la capital quienes se consideraron hinchas Auquistas, Liguistas y posteriormente Nacionalistas (de El Nacional), destacando también a los aficionados por el Deportivo Quito (chullas/azul granas), el América de Quito (cebollitas) y los de Universidad Católica. También se despertaron algunas confrontaciones entre identidades regionales entre Quito y Guayaquil, pues, acorde a la tesis de Ramírez (2017) el fútbol tiene una lectura en clave (identitaria y deportiva) en el plano nacional- regional, que permite la exhibición de los méritos y logros deportivos, al igual que de sus aficiones, un fenómeno que viaja en extensiones más que visibles en el territorio ecuatoriano, y que principalmente se disputa entre las regiones de costa y sierra.

\section{Hinchadas}

Pontón y Pontón (2006) refieren que, posterior a la etapa románti- 
ca, cruza una popular ${ }^{5}$ en el trayecto. Organizaciones prolíferas, más compactas y estructuradas sobre ciertos clubes y el ascenso de la popularidad futbolera, la profesionalización del fútbol ecuatoriano, el manejo de recursos y jugadores experimentados, y (la más importante de todas) el crecimiento paulatino de los simpatizantes, poco a poco cambiarían el sentido de la experiencia: de sólo vivenciar las disputas deportivas o por el honor del fútbol (románticas y recreativas), los aficionados de los clubes, de a pocos fueron convirtiéndose en hinchadas de los equipos relacionando una carga simbólica e identitaria (intra- local) con componentes deportivos y sociales. Establecer quién o quiénes fueron los primeros hinchas en un contexto como el de Ecuador, es difícil, es una tarea que aún no se ha consolidado, sin embargo, bajo estos inmensos fragmentos, puede afirmarse que cada equipo guarda su esencia que le relaciona con elementos que lo hacen diferente de los demás. En el caso del Aucas, existe una vinculación identitaria con la connotación del pueblo, del indio y de papá. "iGana tu equipo, gana el Aucas, ganan los humil-

5 En este escenario, para los autores existen ciertas características: 1) la extensión radical de la popularidad del fútbol y los equipos a nivel nacional. 2) la consolidación del profesionalismo, 3) la relación entre política y fútbol, 4) el surgimiento de pequeñas barras organizadas, 5) la separación espacial por la violencia en los estadios y 6) una diferencia en la estructura social en torno a hinchadas e industria futbolera (Pontón y Pontón 2006, 86). En la etapa popular, también las hinchadas empezaron con procesos organizativos interesantes, algunas hicieron llamarse barras organizadas que referiré posteriormente. des, ganan los aplastados, ésta es la victoria!” (KRÉATIF Televisión 2015), así se definen quienes simpatizan por el equipo que creó la Shell en 1945 y que posteriormente sostuvo el pueblo cuando la inyección de capitales se paralizó. El Aucas es un digno representante del sur de Quito, y como explicó “Don Román", uno de los miembros de la barra Armagedón, la representativa del equipo:

Te hablo de clase media, clase media baja, clase popular, empieza a quererle al Aucas como propio, era el primer equipo con su estadio propio, mucha gente empieza a vincularse por eso. [...] el estadio del Aucas, es un poco más popular, inclusive hasta en el tema de ventas, comida típica. (Román 2019)

En el caso de Liga, los éxitos deportivos que aseguró el equipo durante la etapa popular, le convirtieron en uno de los más representativos del Ecuador, además de ser uno de los de mayor hinchada. Los liguistas, en sus comienzos tenían netamente una afición de carácter universitario, pues, dados los orígenes del equipo en la Universidad Central en 1918, hicieron y hacen que se tenga respeto por dicha institución, además de la clásica portadora en su escudo una "U” mayúscula: de Universitarios, también en el triángulo que dibuja a su camiseta, se dividen los colores rojo y azul, representativos de la ciudad de Quito, esto lo explicó “El Negro” (2019), quien fuere miembro de la "Muerte Blanca", la ba-

6 Por motivos de seguridad y en respuesta a la ética de investigación, los nombres de quienes aparecen aquí responden a pseudónimos 
rra insignia del equipo. En los liguistas, pronto comenzó una expansión masiva por toda la ciudad, alterando otro sentido de pertenencia, el "ser albo", o blanco se convirtió demasiado importante en ese sentido. Las tonalidades desempeñan un punto de identificación con los colores del equipo, además que resaltan todo un significado (apoyado en la teoría del color) de comienzo, perfección, luto y resurrección: todas estas etapas podrían asociarse a ciertos eventos por los que Liga ha pasado en su trayectoria deportiva.

Los Nacionalistas surgieron más tarde, pero responden también a un ejercicio de conformación interesante. Los hinchas despliegan con orgullo el "sentimiento puro criollo", que tal como relató "Flaquito", miembro de "Marea Roja", la barra insignia del equipo, significa:

Ser puro criollo es tener orgullo de haber nacido aquí, en esta patria. Yo creo que mucha gente aquí ama al país, pero no ama ser ecuatoriano, le da vergüenza ser criollo [...] cuando oigo puros criollos no solo estoy orgulloso de mi equipo, sino de lo que representa el jugar sólo con ecuatorianos, mi equipo sí representa $100 \%$ al país, es un orgullo ser un puro criollo más [...] creo que no es necesario que venga ningún extranjero a mí equipo, con todos los ecuatorianos y con un mejor manejo en la parte gerencial podría irle mejor al equipo (Flaquito, 2020)

Los Nacionalistas, también comprenden una cierta influencia militar, pues fueron las FFMM quienes dieron origen al equipo, "solo podían ser pre- sidentes militares, no podían ser civiles, eso cambió hace pocos años atrás y el ejemplo vivo fue que Jorge Yunda fue el primer presidente no militar, presidente civil en el club” (Ibíd.)

\section{De la violencia}

Con la motivación de la explicación anterior, se aplicó una lógica similar en el estudio de las rivalidades quiteñas a partir de una dinámica que contempla el sentido intra- local. Según la RAE, intra se define como "dentro de, en el interior" (RAE, 2020 $)$ y local como "perteneciente o relativo a un territorio, a una comarca o a un país [...] Municipal o provincial. [...] Dicho de un equipo [...] Que compite en su propio campo o terreno de juego. La selección, el jugador local." (Ibíd., 2020B). El carácter de lo intra- local, resulta viable en la comprensión de que ciertas rivalidades (dado el carácter académico y deportivo de esta investigación) fueron en su principio disputas propicias del juego, que poco a poco se adjudicaron significados desarrollados en el transcurso de una etapa romántica con otros sentidos, al interior de la ciudad (como el sector en el que se habita, la simpatía generacional (ser hincha por herencia), o la identificación por elementos simbólico/culturales).

Ramírez (2017) sugiere que existe una relación proporcional entre los logros de campeonato de los equipos y la constitución de hinchadas o barras "a concentração da maioria dos campeonatos em quatro equipes, que gan- 
haram $85 \%{ }^{7}$ das competições disputadas, implicou tambén na constituição das grandes torcidas organizadas ao rededor destes clubes" (Ramírez 2017, 164).

La artesanía que combinó la información provista de crónicas, papers académicos, trabajos de investigación (de tesis de pregrado) y las noticias de los periódicos, permitió la construcción de matrices de investigación con los siguientes resultados: La base de datos madre (con 71 entradas) establece que, no fue sino hasta el 2002 que la prensa empezó a involucrar en su sección de noticias eventos y primicias referidas a la violencia dentro y fuera de los escenarios deportivos. La primera noticia en referencia a las lógicas anteriores, explicaba cómo en uno de los "Clásicos del Astillero" que disputaban Emelec vs Barcelona en Guayaquil el 2 de septiembre de 2002 "al final del cotejo una luz de bengala, lanzada desde la barra de Emelec, impactó en el abdomen de un agente de la Policía [...] que se desplomó inconsciente en la tribuna” (El Universo

7 Para el caso el autor refería (hasta el 2013) a Barcelona, Emelec, Everest, El Nacional, Liga y el Deportivo Quito
2002) en el mismo suceso, también hubo ataques a la prensa, "unos hinchas barcelonistas [...] comenzaron a golpear agresivamente el vidrio de palco de prensa e insultar a un colega de la radio Tricolor, a pesar de que no había realizado ningún comentario en contra del equipo visitante" (El Universo 2002).

Retomando el último artículo de Ramírez y Salazar (2021) En Ecuador el promedio de muertes por año dentro de un escenario deportivo o en enfrentamiento entre hinchas fuera de los graderíos es de apenas 0.38. Cifra absolutamente baja comparada con los 6.44 muertos por año en Colombia o los 6.28 en Perú, por señalar los casos de los países vecinos. En términos absolutos hablamos de 7 fallecidos entre el 2002 y el 2020. Dammert (2007) en su trabajo realizado entre 2004-2007 recuerda que los hechos de violencia eran más entre hinchas y fuerzas policiales que entre miembros de barras organizadas. En la tabla adjunta, veremos los casos de fallecidos en las ciudades de Quito y Guayaquil y los actores involucrados son hinchas de Barcelona, Emelec, LDU, Nacional (los cuatro equipos más exitosos del fútbol ecuatoriano) y la fuerza pública: 
Salazar López, S. S. (2021). Del fútbol en Ecuador: Un análisis sociopolítico del "Jugador número 12" aplicado a la capital. Estudios Latinoamericanos, ISSN (Impr) 0123-0301- ISSN (en línea) 2665-329X, 48-49, 47-68.

Tabla 1 Hinchas fallecidos en Ecuador

\begin{tabular}{|c|c|c|c|}
\hline Fecha & Ciudad & Involucrados & Evento \\
\hline 31.05 .2014 & Quito & Hincha de LDU & $\begin{array}{l}\text { Hincha de Liga de } 17 \text { años, falleció tras } \\
\text { una riña callejera. Según un familiar, el } \\
\text { adolescente estaba 'grafiteando' algo sobre } \\
\text { Liga cuando fue interceptado por un grupo } \\
\text { de jóvenes. }\end{array}$ \\
\hline 7.03 .2014 & Guayaquil & Hincha de Emelec & $\begin{array}{l}\text { Hincha de Emelec, fue asesinado por } \\
\text { supuestos seguidores de otro equipo } \\
\text { mientras se transportaba en un bus de } \\
\text { la cooperativa Panorama, en Guayaquil. } \\
\text { Recibió impactos de piedra lanzados desde } \\
\text { el exterior, que lo dejaron inconsciente. }\end{array}$ \\
\hline 4.11 .2012 & Guayaquil & $\begin{array}{c}\text { Hincha de } \\
\text { Barcelona } \\
\text { Hincha de Emelec } \\
\text { Policía }\end{array}$ & $\begin{array}{l}\text { Hincha de Barcelona fallece por el impacto } \\
\text { de una bala en la cabeza mientras se dirigía } \\
\text { al estadio Monumental para presenciar el } \\
\text { clásico entre su club y Emelec. Supuestos } \\
\text { seguidores del cuadro azul dispararon } \\
\text { al joven a bordo de una camioneta. } \\
\text { Otras imágenes indican que los disparos } \\
\text { pudieron salir de la policía. }\end{array}$ \\
\hline 4.03 .2012 & Quito & Hinchas de LDU & $\begin{array}{l}\text { Hincha de LDU que estaba ubicado en } \\
\text { la general sur del estadio Casa Blanca, } \\
\text { falleció al ser empujado por supuestos } \\
\text { compañeros de la barra Muerte Blanca, } \\
\text { cuando su cabeza se impactó contra el filo } \\
\text { de las gradas del estadio. }\end{array}$ \\
\hline 13.06.2011 & Guayaquil & $\begin{array}{c}\text { Hinchas de } \\
\text { Barcelona } \\
\text { Hinchas de LDU }\end{array}$ & $\begin{array}{l}\text { Hincha de Barcelona, falleció en un centro } \\
\text { de salud en Guayaquil, luego de que fue } \\
\text { brutalmente golpeado por supuestos hinchas } \\
\text { de Liga de Quito, tras el encuentro entre } \\
\text { ambos cuadros en el estadio Monumental. }\end{array}$ \\
\hline 20.06.2009 & Quito & $\begin{array}{c}\text { Hinchas de LDU } \\
\text { Hinchas de } \\
\text { Nacional }\end{array}$ & $\begin{array}{l}\text { Hincha de El Nacional, menor de edad, fue } \\
\text { asesinado supuestamente por hinchas de } \\
\text { la barra Muerte Blanca de LDU, luego de } \\
\text { un enfrentamiento entre ambos elencos en } \\
\text { el estadio Casa Blanca. }\end{array}$ \\
\hline 16.09 .2007 & Guayaquil & $\begin{array}{c}\text { Hinchas de } \\
\text { Barcelona }\end{array}$ & $\begin{array}{l}\text { Un niño murió por el impacto de una } \\
\text { bengala lanzada desde el sector de la } \\
\text { barra Sur Oscura, hacia el sector de suites, } \\
\text { dentro del estadio Monumental, en el } \\
\text { clásico Barcelona vs. Emelec. }\end{array}$ \\
\hline
\end{tabular}

Fuente: Ramírez (2017), Salazar (2021).

Como ya hemos señalado en otros estudios no se puede analizar el caso ecuatoriano sin entender las históricas confrontaciones regionales, sobre todo entre los dos grandes centros de poder: Guayaquil y Quito. A esto hay que sumar los asuntos de las identidades clubísticas, explicados amplia- mente desde la socio-antropología del deporte y, la propia estigmatización y rechazo que recae sobre los hinchas organizados, categorizados como 'barras bravas' (Ramírez, 2017) 


\section{Entenderlo desde la teoría: de las (otras) explicaciones en la violencia en el fútbol}

Quisiera señalar que, no todos los fenómenos de la violencia en el fútbol deberían atribuirse a una suerte de causa y efecto originada desde las barras futboleras, por el contrario, los hallazgos de esta investigación podrían atribuir otras formas o causas también al plano desde los mismos espectadores, o hinchas comunes. La lógica confrontativa del fútbol no sólo es un acto catártico proveniente de las graderías, sino que, también contempla la disputa por la victoria en una forma de naturalización entre los bandos. Las manifestaciones de violencia no son un fenómeno sui generis de nuestros contextos actuales. El punto de vista planteado por Eric Dunning, deriva del planteamiento Eliasino y se complementa en la consideración de que las pautas y niveles de violencia socialmente aceptados, también calan en la explicación que concibe en el sentimiento de placer y el anhelo de atacar a otros seres humanos, como una de las formas de experiencia que se registran en el contexto histórico de ciertas actividades deportivas, pues en comienzo, algunas como el rugby, la caza de zorros y la lucha, también disfrutaban del derramamiento de sangre y otras manifestaciones de violencia física. (Dunning 1992, 301). Respecto de las formas violentas en el fútbol, se dice que rápidamente adquirieron un carácter de corte físico, traducido en el empleo de ataques a/entre jugadores, árbitros y choques entre grupos rivales de aficionados con una forma de "ritualización". Una "agresión ritualizada", que puede ser instintiva y muchas veces no regulada por los parámetros de la norma competentes a la conducta humana (Dunning 1992, 316- 317)

Dunning (1992) refiere también a explicaciones recurrentes a la manifestación de las masculinidades agresivas, formas de agresión, también "ritualizadas", que contienen elementos que están relacionados con las normas centrales de masculinidad de la época: a) resaltan hasta el extremo la rudeza y la habilidad para pelear; b) son, en ese aspecto, distintas en grado- pero no en clase- de las normas de masculinidad en la actualidad dominantes en la sociedad en general; y c) tienden, como consecuencia, a recibir la constante condena de los grupos socialmente dominantes, las normas de hombría que, fueron generadas en la edad Media y principios de la Edad Moderna.

Para Jacques Ramírez (2010) hay una lógica hetero- patriarcal, de la que goza el fútbol y reproduce esas masculinidades agresivas. Un deporte con constituciones masculinas y el desarrollo de luchas o combates en tanto al carácter simbólico de dos grupos. Existe también la influencia de lo corpóreo, entendido como aquellas partes con las que se permite la práctica de ese deporte, esta dimensión que refiere al uso de piernas, pies y genitales supone en la mayoría ${ }^{8}$ de los jugadores, la práctica de un deporte que implica el uso de la parte inferior

8 Con excepción del arquero 
del cuerpo. Retomando a DaMatta, en Ramírez se establece una relación con "los órganos de reproducción y placer [...] están localizados debajo de la cintura, en ese Ecuador simbólico del mundo" (Ramírez 2010, 304). Otro nivel, centra su foco de atención sobre los rituales viriles en tanto a las contiendas de los graderíos. Se marca aquí una importante dimensión frente a las producciones y reproducciones de los múltiples fenómenos de disputa por los espacios e identidades, señalando un potencial de ser focos altísimos de reproducción de masculinidades violentas en detrimento también de las segmentaciones sociales. (Ramírez 2010, 298). Algunas de estas masculinidades son hegemónicas, en tanto permiten "situaciones de violencia doméstica, salud reproductiva y alcoholismo [... en relación a patrones hegemónicos de personificación masculina [...] ignorar o subordinar a las mujeres." (Gutmann y Viveros 2007, 123, 126). O, a decir de Seidler (2009 "el fútbol puede ser una arena en la que toda una gama de emociones varoniles encuentra expresión [...] Aunque también puede ocurrir lo contrario: un resultado desalentador puede traducirse en reacciones violentas." (Seidler 2009, 115)

Otras explicaciones parciales, se adjudican a la desmesurada forma de beber alcohol, ingerir drogas, o golpearse por meramente un ejercicio de catarsis y sensación de placer, sin embargo, no todas las situaciones violentas implican a personas en estado de embriaguez o bajo el efecto de alguna sustancia alucinógena, de igual forma, tampoco todas las manifestaciones de violencia terminan en trifulcas o intercambio de golpes, pues también las hay de corte simbólico o verbal.

Eduardo Archetti (1992) comprende que toda violencia futbolera se ha marcado por el "aguante", definido "como resistencia al dolor y a la desilusión, una resistencia que no conlleva una rebelión abierta, pero sí, a través de los elementos trágicos y cómicos a una serie de posibles transgresiones" (Archetti, 1992, p.266). Está ligado a la relación espacio- habilidad, traducida también en luchas callejeras, intimidaciones y combates, en la que gana el que resiste en la defensa del espacio. Antes de morir, Archetti ya vislumbraba como objetivos en el aguante "la fuerza, la omnipotencia, la violencia y la ruptura de la identidad del otro como elementos centrales de la construcción de su propia identidad" (Archetti, 1984, p.29). Es decir, el aguante se carga de sentido en la medida en que la confrontación con el otro se propicie. Como se conoce popularmente, "el que más aguante es el que vence y humilla al contendor". Pablo Alabarces (2014) y una serie de colegas de los estudios sociales y culturales sobre deporte, le dan el denominativo de teoría, aludiendo que debería tratarse también de una forma de ética, una especie de hibridación de componentes que podría explicarse mejor en sus divisiones de carácter metafórico: la metáfora genital con los "huevos", la metáfora de quienes son padres e hijos en el fútbol (recriminando en los segundos la insuficiencia en los múltiples campos futbole- 
ros), las retóricas del sometimiento sexual ( en Argentina con "vacunas", en Colombia con "culeadas") y otros argumentos de afirmación (o mala reafirmación) masculina y agresiva:

De un lado, los hombres, que son los que aguantan: es decir, los que tienen coraje, los que en consecuencia tienen "huevos"- porque, al ordenarse en torno de metáforas sexuales, todo se vuelve genital, hasta el coraje-, los que se "plantan" y no "corren", asegurando el territorio; los que defienden los "trapos" (las banderas) frente al ataque del adversario. Son los que no precisan aliados, mucho menos la policía, la "yuta"- buchones, botones, tiras, canas, vigilantes, cobanis- que, como usan fierros (armas) y rehúsan en consecuencia la pelea mano a mano, tampoco tienen coraje (Alabarces, 2014, 159)

Utilizar estas (otras) explicaciones sobre la violencia en el fútbol, permitirá entender otro tipo de sentidos que van más allá de las clásicas consignas tradicionales promulgadas especialmente por los medios de comunicación que conllevan al paredón del castigo, al reducir la responsabilidad a las ya satanizadas "barras bravas" de los equipos de fútbol. Si bien en la mayoría de sucesos violentos (que señala la prensa) están involucradas barras o hinchadas, es momento para comprender y resignificar el apelativo que de "bravas" se les ha acuñado.

\section{Conclusiones}

Primero: el fenómeno de la violencia en el fútbol no es algo recien- te, pues tiene sus orígenes desde la segunda mitad del siglo XX en Inglaterra con las manifestaciones de los hooligans y en Argentina con los efectos de las barras bravas. 50 años más tarde, el fenómeno aterrizaría en suelo ecuatoriano, a partir de 2002 con las primeras beligerancias en la ciudad de Guayaquil, dejando como saldo más de 100 heridos, 7 muertos y 82 detenidos hasta la fecha. En segundo lugar: Los estudios sociales y culturales sobre deporte, y la sociología del deporte, brindaron las herramientas teóricas y analíticas para llegar a la comprensión de que, los fenómenos deportivos también calan en las explicaciones que de las ciencias sociales derivan. Es interesante utilizar estos aparatajes para llevarnos a mejores y más refinadas explicaciones sobre los fenómenos social/deportivos, como la violencia en el fútbol a partir de una óptica diferente de trabajo. En tercera consideración: Para el caso quiteño, las conformaciones y asociaciones de hinchadas se explican por la transición de una etapa romántica hacia una popular. Además de ello, es propicio considerar que el fútbol desplegó un espacio para la anexión hacia nuevas formas de identificación, bien sea en una clave nacional- regional, local- intra- local. En cuarto lugar, existen otro tipo de explicaciones de la violencia en el fútbol, tales como: los niveles socialmente aceptados de violencia, la agresión ritualizada, las masculinidades agresivas/hegemónicas y las lógicas del aguante. 
Salazar López, S. S. (2021). Del fútbol en Ecuador: Un análisis sociopolítico del "Jugador número 12" aplicado a la capital. Estudios Latinoamericanos, ISSN (Impr) 0123-0301- ISSN (en línea) 2665-329X, 48-49, 47-68.

\section{Quinto: Barrismo social ecuatoriano}

Por último, a menera de hipótesis, planteamos que las actividades de los hinchas en torno al barrismo social puede empezar a entenderse como un movimiento social que reivindica un sentimiento de identidad clubística, de hinchas pertenecientes a una barra organizada, que se agrupan con fines sociales y políticos y que tienen un fuerte matiz popular. Se requiere más investigación, no solo en los países analizados en este estudio, sino en otros contextos para tener mayores elementos de análisis comparativo.

Una de las conclusiones más importantes de este trabajo radica en que, al partir de la premisa de que, ni el barrismo, ni el hinchismo son vandalismos, aún en Ecuador existen algunas acciones incipientes en tanto son manifestaciones presentes que hoy deberíamos tener en consideración, (al igual que los clubes y las instituciones futboleras). Hay múltiples sentidos que mueven esta dinámica en tanto a

Acciones encaminadas a redimensionar las formas de expresión y las prácticas de los integrantes de las barras de fútbol que inciden negativamente en los ámbitos individual, comunitario y colectivo, y de potenciar los aspectos positivos que de la esencia del barrismo deben rescatarse. Esta propuesta se fundamenta en procesos formativos tales como el diálogo de saberes, que recogen valores sociales, normas, creencias, ideales y sentimientos, y le permiten a los barristas resignificar la realidad que los sumerge en su pasión por el mundo del fútbol, y asumir así su identidad como sujetos sociales y participativos" (Ministerio del Interior 2014- 2024, 7- 8)

A partir de otro rastreo provisto de fuentes de internet para esta investigación, se encontró que entre 2019 y 2020, se registraron más de 15 intervenciones comunitarias en la ciudad entre las barras Marea Roja, Muerte Blanca y Armagedón, siendo la primera la de mayor accionar. Las recaudaciones de fondos, posteos sobre los emprendimientos y negocios de los hinchas, y las rifas solidarias, entre otras, promovían el lenguaje de la solidaridad entre los miembros de Muerte Blanca y Armagedón, especialmente en pleno contexto de pandemia. No obstante, llamó mi atención la convocatoria de Marea Roja a las ollas comunitarias, cuyo proceso reunía a sus miembros para proveer de alguna comida diaria (especialmente almuerzos) a quienes más lo necesitaron durante los meses más álgidos del 2020:

Proyecto social que venimos realizando para ayudar a las personas más necesitadas. Por favor no te quedes sin comer ni mandes a tus hijos a la cama sin hacerlo. Si necesitas ayuda no dudes en avisarnos, que de lo mucho o poco que tengamos de seguro lo podemos compartir. Si deseas ser parte y colaborar con esta iniciativa escríbenos por interno. iSOMOS MAREA ROJA, la hinchada del pueblo para el pueblo! (Marea Roja 2020)

El barrismo social ya es un hecho en el Ecuador, sólo necesita de mejores canales de articulación y de desprenderse de cier- 
tas prácticas herméticas, que no permiten la negociación o acercamientos entre barras. La solidaridad como lenguaje de los pueblos es una consigna de la que no están exentos quienes intervienen en estas causas, pues es un buen momento para seguir en crecimiento y resignificar las prácticas barristas

\section{Referencias}

Alabarces, P. (2000). "Aguante y represión. Fútbol, violencia y política en la Argentina" en Alabarces, P. (comp.) Peligro de gol. Estudios sobre deporte y sociedad en América Latina. Buenos Aires: CLACSO-ASDI.

Alabarces, P. (2014). Héroes, machos y patriotas. El fútbol entre la violencia y los medios. Buenos Aires: Aguilar.

Alabarces, P. (2020). Clase con Pablo Alabarces. Clase de Seminario de Estudios Sociales y Culturales sobre Deporte. Montevideo.

Archetti, E. (1984). Fútbol y Ethos. Buenos Aires: FLACSO, serie investigaciones.

Archetti, E. (1992). “Calcio: un rituale di violenza?”. En P. (. Lanfranchi, Il calcio e il suo pubblico. Napoli: Edizione Scientifiche Italiane.

Arévalo, Chela, y Tito Adalí. (2019). Comunicación, violencia y construcción de identidades. Análisis del mensaje en tres cánticos de la barra organizada del Club Deportivo El Nacional. Caso estudio: "Marea Roja”. Quito: Trabajo de titulación modalidad Proyecto de investigación previo a la obtención del Título de Comunicador Social, con énfasis en Periodismo- Universidad Central.

Barras bravas siempre inquietan el ambiente. (3 de 09 de 2002). El Universo. Obtenido de:https://www.eluniverso.com/2002/09/03/0001/15/73A44F127FDE4418B42F78C1B32CE281.html

Bromberger, Ch. (1994). "La pasión futbolística y la Copa del Mundo: ¿por qué tanto ruido y tanta furia?”, en Sudgen, J. y Tomlinson, A. (eds.) Host and Champions. Arena: Aldershot.

Bustamante, Fernando. (2006). «Esbozos para una historia social del fútbol ecuatoriano.» En Biblioteca del fútbol ecuatoriano: Quema de tiempo y área chica. Fútbol e historia, de Fernando Carrión. Quito: FLACSO- Ecuador

Bustamente, Gerardo. (2002). ¿Cuánto sabe usted de Fútbol? para aficionados y deportistas. Quito: PPL Impresiones.

Carrión, Fernando. (2006). «La historia y geografía del fútbol.» En Biblioteca del futbol ecuatoriano: Quema de tiempo y área chica. Fútbol e historia, de Fernando Carrión Comp. Quito: FLACSO- Ecuador

Castro, J. (2013). El aguante en una barra brava: apuntes para la construcción de su identidad. FOLIOS - Segunda época, 167-184. Obtenido de http://www.scielo.org.co/ pdf/folios/n38/n38a13.pdf

Dammert, M. (2007). Fútbol y violencias en el Ecuador: Espectáculo y análisis. Ciudad segura 21, 4-10.

Dunning, E. (1992). Lazos sociales y violencia en el deporte. En N. Elias, \& E. Dunning, Deporte y ocio en el proceso de la civilización. México: Fondo de Cultura Económica.

Dunning, E., Murphy, P., \& Williams, J. (1992). La violencia de los espectadores en los partidos de futbol: hacia una explicación sociológica. En N. Elías, \& E. Dunning, De- 
Salazar López, S. S. (2021). Del fútbol en Ecuador: Un análisis sociopolítico del "Jugador número 12" aplicado a la capital. Estudios Latinoamericanos, ISSN (Impr) 0123-0301- ISSN (en línea) 2665-329X, 48-49, 47-68.

porte y ocio en el proceso de la civilización. México: Fondo de Cultura Económica. Eidelstein, O. (2016). Congreso internacional de lucha contra la violencia en el fútbol. Panel: Experiencias internacionales, (págs. 1- 17). Buenos Aires.

El Universo. (3 de 09 de 2002). Barras bravas siempre inquietan el ambiente. El Universo. Obtenido de https://www.eluniverso.com/2002/09/03/0001/15/73A44F127FDE4418B42F78C1B32CE281.html

Elias, N., \& Dunning, E. (1992). Deporte y ocio en el proceso de la civilización. México, D.F: Fondo de Cultura Económica.

Elias, N. (2008). Sociología fundamental. España: Gedisa.

Flaquito. (06 de 06 de 2020). Conversación casual por WhatsApp.

García, M., Legardera, F., \& Puig, N. (2017). Deporte y sociedad global: la perspectiva sociológica. En M. García, F. Lagardera, R. Llopis, N. Puig, \& A. Vilanova (comps), Sociología del Deporte (págs. 15- 38). Madrid: Alianza editorial.

Gutmann, M., \& Viveros, M. (2007). Masculinidades en América Latina. En M. Aguilar (Coordinador), Tratado de psicología social: perspectivas socioculturales. BarcelonaMéxico: Anthropos - UAM Iztapalapa.

Hill, Randy. (2015) ANÁLISIS DEL RITUAL Y EL MENSAJE QUE EXPRESA LA "MUERTE BLANCA”, BARRA DE LIGA DEPORTIVA UNIVERSITARIA DE QUITO. Quito: Trabajo de titulación modalidad Proyecto de investigación previo a la obtención del Título de Comunicador Social. Universidad Central.

Hobbs, D., \& Robins, D. (1991). The boy donne good: Footbal, violence,changes and continuitis. Sociologycal Rewiew, Vol. 39, 53- 85.

Lisotto, P. (07 de 12 de 2018). La historia del verdadero Jugador Nro 12 que identifica a Boca y su conexión con Madrid. La Nación. Obtenido de https://www.lanacion.com. ar/deportes/futbol/la-historia-del-verdadero-jugador-nro-12-nid2200211

Los actos de violencia en el fútbol ecuatoriano en una década. (7 de 02 de 2017). El Comercio. Obtenido de https://www.elcomercio.com/deportes/violencia-futbol-ecuador-barrasbravas-deportes.html

Magazine, R. (2008). Azul y oro como mi corazón: Masculinidades, juventud y poder en una porra de los Pumas de la UNAM. CDMX: Universidad Iberoamericana.

Marea Roja. (03 de 08 de 2020). Facebook. Recuperado el 06 de 08 de 2020, de https:// www.facebook.com/watch/?v=749582712499669

Ministerio del Interior. (2014- 2024). Plan Decenal de Seguridad, Comodidad y Convivencia en el Fútbol. Bogotá: Gente Nueva. Obtenido de https://adsdatabase.ohchr.org/IssueLibrary/COLOMBIA_Plan\%20Decenal\%20de\%20Seguridad\%20Comodiad\%20 y\%20Convivencia\%20en\%20el\%20Futbol\%202014-2024.pdf

Negro, E. (19 de 09 de 2019). Entrevista en profundidad mientras almorzaba. (S. Salazar, Entrevistador)

Perugachi, José. (2018). Para los indígenas ni acceder a los deportes fue fácil. Un análisis de las comunidades de San Pablo de Lag, del cantón de Otavalo a través de la práctica del fútbol . Quito.

Pontón, C., \& Pontón, D. (2006). Breve historia de las grandes rivalidades en el fútbol ecuatoriano. En e. Carrión, \& Fernando, El jugador número 12: Fútbol y sociedad (págs. 75- 109). Quito: FLACSO.

Pugna entre columnas de barra Sur Oscura tiene antecedentes. (7 de 02 de 2017). El Universo. Obtenido de https://www.eluniverso.com/deportes/2017/02/07/nota/6036433/ pugna-columnas-barra-tiene-antecedentes 
RAE. $\left(2020^{\mathrm{a}}\right)$. rae.es. Recuperado el 04 de 05 de 2020, de https://dle.rae.es/local?m=form RAE. (2020B). rae.es. Recuperado el 05 de 04 de 2020, de https://dle.rae.es/intra-?m=form Ramírez, J. (2010). Breves apuntes teóricos para acercarse al problema de las relaciones entre fútbol, masculinidad y violencia. En S. Martínez (Coordinador), fútbol- espectáculo, cultura y sociedad. México: Afinita Editorial.

Ramírez, J. (2017). Torcidas organizadas, territórios e violencia no futebol equatoriano. En B. Borges, B. de Hollanda, \& O. Rodríguez Org., Torcidas organizadas na América Latina. Estudios comtemporaneos (págs. 154- 173). Río de Janeiro: Viveiros de Castro Editora.

Redondo, I. (20 de 06 de 2016). La semilla de la violencia 'hooligan'. Marca. Obtenido de https://www.marca.com/futbol/eurocopa/2016/06/20/57679352468aeb33708b4644. html

Román, D. (13 de 01 de 2019). Historia de Aucas y Armagedón: Conversación casual en un café cercano a Flacso. (S. Salazar, Entrevistador)

Santos, T. (2003). "O lado hard da Cultura cool: as torcidas e a violencia no fútbol”, en P. Alabarces (coord) Futbologías. Fútbol, identidad y violencia en América Latina. Buenos Aires: CLACSO.

Sampieri, R., Fernández, C., \& Baptista, P. (2014). Metodología de la investigación. México: McGRAW-HILL / INTERAMERICANA EDITORES, S.A. DE C.V.

Salazar, S. (2021). Entre hinchas y barras: Un análisis sociopolítico aplicado a la capital del Ecuador (2002-2020). Quito: Tesis (Maestría de Investigación en Sociología Política)-FLACSO Ecuador.

Seidler, V. (2009). “La violencia: ¿el juego del hombre?”. En J. Ramírez (coordinador), Masculinidades: el juego de género de los hombres. México: Plaza y Valdés.

Seminario de estudios sociales y culturales sobre deporte. (2020). https://isef.udelar.edu. uy/. Recuperado el 10 de 03 de 2020, de https://isef.udelar.edu.uy/noticias/curso-seminario-de-estudios-sociales-y-culturales-sobre-deporte/

Szlifman, J. (2020). El crímen que dio nacimiento a las barras bravas argentinas. Revista Líbero. Obtenido de https://revistalibero.com/blogs/contenidos/el-crimen-que-dio-nacimiento-a-las-barras-bravas-argentinas

Velásquez, Javier. (2006) «Historia del fútbol ecuatoriano desde Guayaquil.» En Biblioteca del fútbol ecuatoriano: Quema de tiempo y área chica. Fútbol e historia, de Fernando Carrión Compilador. Quito: FLACSO- Ecuador. 